\title{
Estradiol on Trigger Day was Irrelevant to Live Birth Rates of Fresh Cycles but Positively Associated with Cumulative Live Birth Rates: A Multicenter Retrospective Study
}

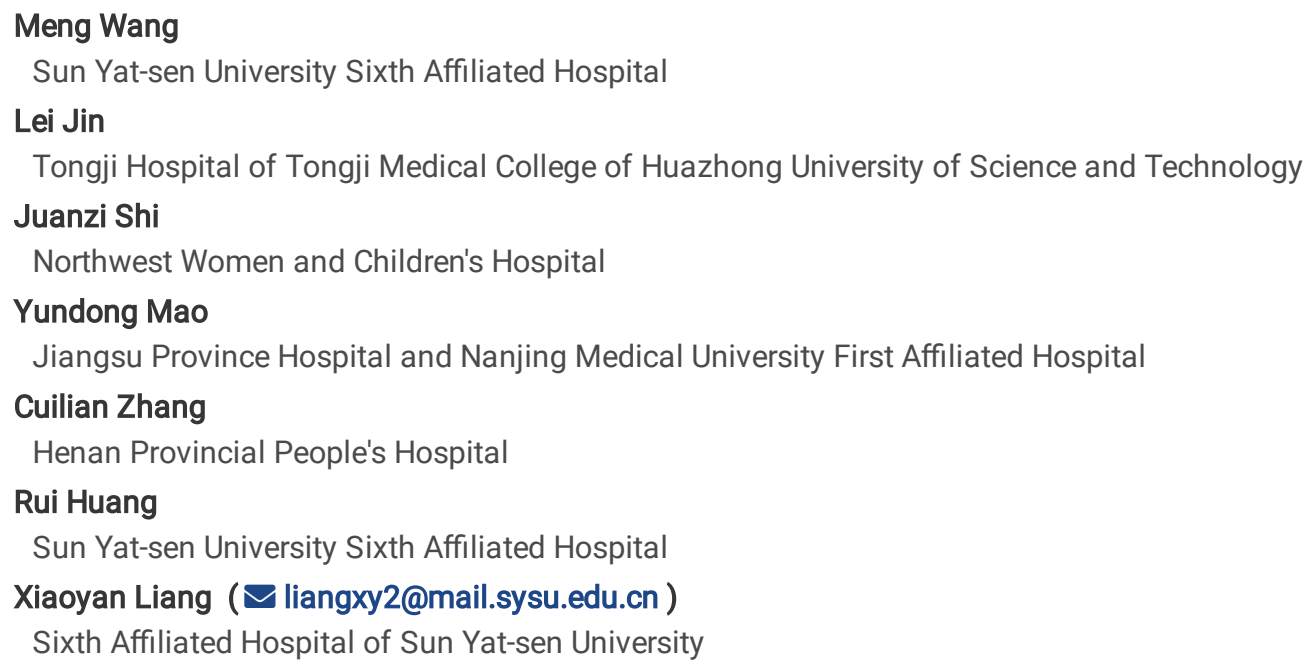

Research

Keywords: estradiol, preimplantation embryo development, pregnancy rate, live birth rate, cumulative live birth rate

Posted Date: July 7th, 2021

DOI: https://doi.org/10.21203/rs.3.rs-673358/v1

License: (c) (i) This work is licensed under a Creative Commons Attribution 4.0 International License. Read Full License 


\section{Abstract}

Background: Serum estradiol (E2) level is supraphysiological during controlled ovarian stimulation (COS). However, the impacts of high levels of E2 on the development of preimplantation embryos, live birth rates in fresh and frozen-thawed embryo transfer (FET) cycles, and cumulative live birth rates (CLBR) remain debatable.

Methods: This retrospective study included 93,959 oocyte retrieval cycles of 73,794 patients performing in vitro fertilization (IVF)/intracytoplasmic sperm injection (ICSI) from 2013 to 2018 in five reproductive centers in China. Patients were categorized according to E2 level on trigger day: $<1,000,1,000-2,000,2,000-3,000,3,000-4,000,4,000-5,000$ and $\geq 5,000 \mathrm{pg} / \mathrm{ml}$. Developments of embryos were evaluated by specific stage embryo rates, fertilization rates and cleavage rates. Generalized linear mixed models and multilevel models were adopted. Univariate and multivariate analysis were performed to adjust for the confounding factors.

Results: Compared with the $<1,000 \mathrm{pg} / \mathrm{ml}$ group, the aMD $(95 \% \mathrm{Cl})$ for the specific stage embryo rates in groups 2-6 were $-0.10(-0.11,-0.10)$, $-0.13(-0.14,-0.12),-0.14(-0.15,-0.13),-0.15(-0.16,-0.15)$ and $-0.14(-0.15,-0.13)$, respectively. The adjusted odds ratio (aOR) and $95 \%$ confidence interval $(\mathrm{Cl})$ of live birth of fresh cycles in the stratified higher E2 groups was $1.03(0.91,1.16), 1.06(0.93,1.21), 1.03(0.89,1.19)$, $1.02(0.87,1.20)$ and $0.88(0.75,1.03)$, while the aOR $(95 \% \mathrm{Cl})$ for live birth in FET cycles was $1.01(0.90,1.14), 1.08(0.95,1.22), 1.10(0.96$, 1.27), $1.12(0.97,1.29)$, and $1.20(1.05,1.37)$, respectively. When E2 $<14,000 \mathrm{pg} / \mathrm{ml}$, E2 was positively correlated with CLBR, otherwise, E2 was irrelevant to CLBR.

Conclusion: High levels of E2 is associated with decreased rates of properly developed embryos. When E2 level is above $5,000 \mathrm{pg} / \mathrm{ml}$ on trigger day, the E2 level is associated with increased live birth rates in FET cycles. While the live birth rates in fresh cycles is not impacted. CLBR is positively associated with E2 on trigger day when E2 is $<14,000 \mathrm{pg} / \mathrm{ml}$.

\section{Background}

Controlled ovarian stimulation (COS) with gonadotrophin recruits multiple dominant follicles within a treatment cycle for infertile women, increasing the number of oocytes retrieved and embryos formed, which in turn, multiplies the cumulative live birth rates (CLBR) and saves time for patients [1]. The level of serum estradiol (E2) reaches $500-10,000 \mathrm{pg} / \mathrm{ml}$ during COS, whereas maintains $200-400 \mathrm{pg} / \mathrm{ml}$ in natural cycles [2, 3]. The serum E2 is higher in the fresh embryo transfer cycle than the frozen-thawed embryo transfer cycle (FET) and the spontaneous pregnancy until 7-8 gestational weeks [4]. Supraphysiological E2 has been considered to impair endometrium receptivity, modify the implantation window [5, 6], and induce fetal growth restriction by suppressing the embryo implantation [7] and vacuolization of placenta in fresh cycles [8]. However, the impacts of high levels of E2 on the developments of preimplantation embryos, live birth rates in fresh and FET cycles, and CLBR remain debatable.

Some studies reported that the supraphysiological E2 level was correlated with the decline in embryo quality $[9,10]$, implantation rates, pregnancy and live birth rates in both fresh [7] and FET [11] cycles. Some reports suggested that serum E2 levels did not impact the development of embryos, $[12-14]$ pregnancy and live birth rates $[15,16]$. While other research concluded the E2 levels were positively correlated with the live birth rates in fresh cycles [17-19].

The relationship between the CLBR and E2 levels during COS also remained unclarified. Merely one study suggested that the relationship between CLBR and E2 was an inverted U-shaped, while the association was not significant after adjusting for confounding factors [20].

Since the aforementioned studies were conducted in single centers, and no consensus have been achieved on the impacts of high E2 during COS, the investigators aim to further explore the relationship between the levels of E2 on trigger day and the embryo developments, as well as the pregnancy outcomes of in vitro fertilization (IVF)/intracytoplasmic injection (ICSI), based on the data of five reproductive centers in China.

\section{Methods}

\section{Study Design}

The investigators conducted a multicenter, retrospective cohort study to explore the impacts of high levels of E2 on trigger day on preimplantation embryo developments, pregnancy rates and live birth rates of fresh and FET cycles, and CLBR. The present study involved autologous oocyte IVF/ICSI cycles performed between January 2013 and December 2018 at five reproductive centers in China. All cycles were followed up until December 2019. Cycles with any of the following conditions were excluded: (1) the E2 level was unavailable on trigger day; (2) abnormal karyotypes in either of the couple; (3) the embryos were generated using frozen or donor gametes, oocytes in vitro maturation, or non-ejaculated sperms; (4) two or more fertilization methods (e.g., IVF, ICSI, and rescue ICSI) were applied in a single cycle; (5) embryo biopsies were performed for the preimplantation genetic screening/diagnosis. For the analysis of pregnancy rates, live birth rates and CLBR, 
the investigators further excluded women with the diagnosis of adenomyosis, leiomyomas, intrauterine adhesion, endometrial polyps, uterine malformation, and cervical excisions. The recruited cycles were divided into groups 1 to 6 according to the serum E2 concentration on trigger day [21]: $<1,000,1,000-2,000,2,000-3,000,3,000-4,000,4,000-5,000$ and $\geq 5,000 \mathrm{pg} / \mathrm{ml}[21]$.

The present study obtained approvals from the Ethics Committees at the Sixth Affiliated Hospital of Sun Yat-sen University (2020ZSLYEC295), Tongji Hospital of Tongji Medical College of Huazhong University of Science and Technology (TJ-IRB20210320), Northwest Women's and Children's Hospital (2019013), Henan Provincial People's Hospital (SYSZ-LL-2019110401), and Jiangsu Provincial Hospital (2020-SR046). The written informed consents were waived by the ethics committees because of the retrospective nature of the study.

\section{Procedures}

For the ovarian stimulation, clinicians at each center applied gonadotropin-releasing hormone agonist (GnRH-a), GnRH antagonist (GnRHant), progestin primed ovarian stimulation (PPOS), mild stimulation protocols, and natural cycle protocols following local routine. When the diameter of at least one follicle reached $18 \mathrm{~mm}$, human chorionic gonadotrophin (HCG) or GnRH-a (for patients with high risk of ovarian hyperstimulation syndrome) was administered for triggering. After 34-36 hours, the oocytes were retrieved. IVF or ICSI was performed depending on the sperm quality. According to the diagnosis and treatment histories of patients, natural cycle, hormone replacement therapy (HRT), ovarian stimulation cycle and down regulation cycle were applied for the endometrium preparation in FET cycles.

Based on the ovarian response, endometrium, and the willingness of patients, the fresh or frozen-thawed cleavage embryos or blastocysts were transferred to the uterine. The investigators classified the embryos at day 3, 5 and 6 into good-quality and not-good-quality. Good quality embryos included the following: (I) cleavage embryos on day 3 with $\leq 20 \%$ fragments, and $\geq 7$ blastomeres which were uniform in size [22]; (II) grade 3-6 blastocysts (day 5 and 6), with grade A or B for the inner cell mass and trophectoderm, according to the Gardner's system [23].

\section{Outcome measures}

The primary outcome was the CLBR in a complete cycle, where all embryos from one retrieval were used up, or at least one live birth was achieved. The secondary outcomes included the preimplantation embryo developments, biochemical pregnancy rates (serum $\beta-\mathrm{HCG}>5 \mathrm{IU} / \mathrm{L}$ after 10 days of embryo transfer), clinical pregnancy rates (the observation of gestational sacs by transvaginal ultrasound), live birth rates (a live-born infant at least after 22 gestational weeks) in fresh and FET cycles.

Preimplantation embryo development was evaluated by the specific-stage embryo rates (the proportion of embryos with 6-8 cells on day 3 in 2-pronucleus-derived cleavage embryos), fertilization rates (for IVF: the proportion of 2-pronucleus fertilized oocytes in oocytes to be fertilized; for ICSI: the proportion of 2-pronucleus fertilized oocytes in metaphase II oocytes), and cleavage rates (the proportion of cleavage embryos in 2-pronucleus fertilized oocytes).

\section{Statistical analysis}

Normally distributed continuous variables were expressed as mean \pm standard deviation. Intergroup differences were tested by one-way analysis of variance. Skewed distributed continuous variables were expressed in median and interquartile range. The Kruskal-Wallis test was applied for intergroup comparisons. Categorical variables were presented as frequencies with percentages, and intergroup differences were compared using chi-square test.

The investigators formulated generalized linear mixed (GLIMMIX) models to fit the outcomes of specific-stage embryo rates, fertilization rates, and cleavage rates, since some patients underwent multiple ovarian stimulations and oocytes retrievals. The reproductive centers and medical record number of patients were taken as random effects, and the remaining factors were regarded as fixed effects. The covariance parameters for these random effects were included in the covariance matrix of residuals.

Multilevel models were used to fit the biochemical pregnancy rates, clinical pregnancy rates, and live birth rates, since the hierarchical structure of the 3-level data with cycles (level 1) nested within patients (level 2) nested within the reproductive centers (level 3). Multiplicity was adjusted using Dunnett's test. The generalized additive model was used to generate the smooth curve for the CLBR to E2 on trigger day.

The following potential confounders were adjusted in the GLIMMIX models: maternal age at oocyte retrieval, body mass index (BMI), paternal age at oocyte retrieval, infertility type, infertility duration, infertility indications, antral follicle count, basal level of follicle-stimulating hormone (FSH), basal level of luteinizing hormone (LH), COS regimens, stimulation duration, total gonadotropin dose, LH on trigger day, progesterone on trigger day, fertilization method, and reproductive centers. Additionally, the quality, number and developing days of embryos transferred, the endometrium preparation methods of FET cycle, and the endometrium thickness on trigger day (fresh cycle) or transformation day (FET cycle) were also included in the model fitting for the pregnancy rates, live birth rates and CLBR. The number of oocytes retrieved, and freezeall or not were also adjusted in the model fitting for CLBR. 
Multilevel multiple imputations were made for variables with missing values. The adjusted mean difference (aMD), adjusted odds ratio (aOR), and $95 \%$ confidence intervals $(\mathrm{Cl})$ were presented. All analyses were conducted on the GLIMMIX, NLMIXED and GAM procedure of SAS version 9.4. $P<0.05$ was considered statistically significant.

\section{Results}

The present study enrolled 93,959 oocyte retrieval cycles of 73,794 patients. Groups 1-6 included 20,641, 21,307, 16,613, 11,793, 9,379 and 14,226 cycles, respectively. Furthermore, 45,852 cycles of 42,315 patients underwent fresh embryo transfer. Subsequently, 56,760 FET cycles of 40,674 patients were performed. A total of 45,620 patients performed 49,214 complete cycles (Figure 1 ).

The baseline characteristics significantly differed among groups (Table 1). Patients with higher E2 tended to possess younger age, lower BMI, basal FSH and lower proportions of diminished ovarian reserve, but the proportions of primary infertility and the use of GnRH-a regimen were higher. The antral follicle counts, total gonadotrophin dose, progestin level on trigger day, and the number of oocytes retrieved were higher with the increase of E2. The rates for specific-stage embryos $(0.84 \pm 0.24)$, IVF fertilization rates $(0.72 \pm 0.35)$, and ICSI fertilization rates $(0.78 \pm 0.31)$ were highest in group $1(\mathrm{E} 2<1000 \mathrm{pg} / \mathrm{ml})$. The difference in cleavage rates among groups were limited, even if there were statistical significance (Table 1).

The multivariate analysis of the preimplantation embryo developments of the 6 groups were displayed at Table 2. After adjusting for confounding factors, E2 on trigger day was negatively correlated to the IVF and ICSI fertilization rates, and specific stage embryos rates. Compared with group 1 , the aMD $(95 \% \mathrm{Cl})$ for the specific stage embryo rates in groups $2-6$ were $-0.10(-0.11,-0.10),-0.13(-0.14,-0.12),-0.14$ $(-0.15,-0.13),-0.15(-0.16,-0.15)$ and $-0.14(-0.15,-0.13)$, respectively. The differences of IVF and ICSI fertilization rates between group 1 and groups 2-6 were limited (0.02-0.04), although there were statistic significances. Furthermore, the cleavage rates in group 1 and the higher E2 groups (groups 2-6) had no significant difference in the multivariate model.

The demographic characteristics and treatment information revealed a significant difference among groups for patients who underwent fresh embryo transfer cycles (Table 3), FET cycles (Table 4), and complete cycles (Table 5). The tendency was similar to that of the recruited oocyte retrieval cycle. In addition, the proportion for day 3 embryos decreased as the E2 level increased in both fresh and FET cycles. The live birth rate was highest in group 5 (E2: 4,000-5,000 pg/ml) for fresh embryo transfer cycles (52.8\%), and in group 6 ( $\geq 5,000 \mathrm{pg} / \mathrm{ml})(55.1 \%)$ for FET cycles. The CLBR was highest (83.8\%) in group 6.

In fresh embryo transfer cycle, the multivariate analysis revealed that the E2 on trigger day was not associated with biochemical pregnancy, clinical pregnancy, and the live birth rate (Table 6). Compared with $\mathrm{E} 2<1,000 \mathrm{pg} / \mathrm{ml}$, the aOR $(95 \% \mathrm{Cl})$ of biochemical pregnancy rates in higher E2 groups were $1.06(0.94,1.19), 1.12(0.99,1.27), 1.05(0.91,1.22), 1.04(0.89,1.22)$, and $0.94(0.80,1.11)$, respectively; the aOR $(95 \%$ $\mathrm{Cl})$ of clinical pregnancy rates in higher E2 groups were $1.06(0.94,1.20), 1.11(0.97,1.27), 1.04(0.90,1.20), 1.07(0.91,1.25)$, and $0.90(0.76$, $1.05)$, respectively; and the aOR $(95 \% \mathrm{Cl})$ of live birth rates were $1.03(0.91,1.16), 1.06(0.93,1.21), 1.03(0.89,1.19), 1.02(0.87,1.20)$, and $0.88(0.75,1.03)$, respectively.

In FET cycle, the multivariate analysis showed that when E2 was higher than $5,000 \mathrm{pg} / \mathrm{ml}$, E2 on trigger day was positively correlated to the clinical pregnancy rates and live birth rates. Compared to group 1, the aORs $(95 \% \mathrm{Cl})$ of clinical pregnancy rates in groups 2-6 were $1.04(0.92$, 1.17), $1.14(1.00,1.30), 1.14(0.99,1.31), 1.14(0.99,1.32)$, and $1.21(1.06,1.39)$, respectively; the aORs $(95 \% \mathrm{Cl})$ of live birth rates in groups $2-$ 6 were $1.01(0.90,1.14), 1.08(0.95,1.22), 1.10(0.96,1.27), 1.12(0.97,1.29)$ and $1.20(1.05,1.37)$, respectively. The proportion of biochemical pregnancy cases in group $2(\mathrm{aOR}=1.16,95 \% \mathrm{Cl}=1.02-1.32)$ and group $6(\mathrm{aOR}=1.21,95 \% \mathrm{Cl}=1.06-1.40)$ was significantly higher, when compared to group 1 . However, the biochemical pregnancy rates were comparable between groups 2, 4-5 and group 1, after adjusting for the confounders (Table 7).

The CLBR for the 49,214 complete cycles was $62.3 \%$. The smooth curve fitted for CLBR on E2 revealed that for every $1,000 \mathrm{pg} / \mathrm{ml}$ increase in E2, when E2 was $<5,500 \mathrm{pg} / \mathrm{ml}$, the CLBR increased by approximately $10 \%$, when E2 was between $5,500-13,281 \mathrm{pg} / \mathrm{ml}$, the CLBR increased by approximately $1.8 \%$, and when E2 was $>13,281 \mathrm{pg} / \mathrm{ml}$, the CLBR decreased by $3 \%$ (Figure 2). Based on the smooth fitting curve, the investigators formulated the multivariate analysis with expanded E2 groups. The results revealed that when E2 was within 1,000-14,000 $\mathrm{pg} / \mathrm{ml}$, the high level of E2 was correlated to the increase in CLBR. Compared with E2 $<1,000 \mathrm{pg} / \mathrm{ml}$, the aOR ( $95 \% \mathrm{Cl})$ of the CLBR for the E2 groups of $1,000-2,000 \mathrm{pg} / \mathrm{ml}, 2,000-3,000 \mathrm{pg} / \mathrm{ml}, 3,000-4,000 \mathrm{pg} / \mathrm{ml}, 4,000-5,000 \mathrm{pg} / \mathrm{ml}, 5,000-6,000 \mathrm{pg} / \mathrm{ml}, 6,000-8,000 \mathrm{pg} / \mathrm{ml}, 8,000-10,000$ $\mathrm{pg} / \mathrm{ml}, 10,000-120,000 \mathrm{pg} / \mathrm{ml}$, and 120,000-140,000 pg/ml were 1.33 (1.13,1.56), 1.56 (1.31,1.85), 1.68 (1.39,2.02), 1.83 (1.50,2.24), 1.86 $(1.49,2.33), 1.88(1.51,2.34), 1.92(1.46,2.54), 1.82(1.26,2.65)$, and $1.92(1.09,3.41)$, respectively. When E2 was higher than $14,000 \mathrm{pg} / \mathrm{ml}$, this was irrelevant to the CLBR (Table 8$)$.

\section{Discussion}


The present study is the first multicenter study conducted with the largest dataset that focused on the associations between the supraphysiologic E2 level, and preimplantation embryo development and pregnancy outcomes in fresh embryo transfer, FET, and complete cycles. The present results revealed the negative association of the E2 level on trigger day and the IVF/ICSI fertilization rates, and specific stage embryo rates. Live birth rate in fresh cycle was not impacted by the high E2 on trigger day, while E2 level was correlated to the increase in live birth rates in FET cycles. The E2 level had a segmental relation to the CLBR: when E2 was lower than 14,000 pg/ml, E2 was positively correlated to CLBR; when E2 was $>14,000 \mathrm{pg} / \mathrm{ml}$, E2 was irrelevant to the CLBR.

The present results for the specific-stage embryo rates (embryos developing to 6-8 cells on day 3), and IVF/ICSI fertilization rates were consistent with those in previous studies, suggesting that the high level of E2 impaired the development of preimplantation embryos [10, 12, 24]. However, when E2 was $<5,000 \mathrm{pg} / \mathrm{ml}$, the live birth rates for the fresh and FET cycles, and the CLBR did not decrease when E2 increased. This phenomenon indicates that the impact of elevated E2 levels on the development potentials of embryos is limited.

The clinical pregnancy and live birth rates in fresh cycles were the highest in group $5(4,000-5,000 \mathrm{pg} / \mathrm{ml})$. After adjusting for the confounders, the clinical pregnancy and live birth rates of E2 $\geq 5000 \mathrm{pg} / \mathrm{ml}$ were lower than those of E2 $<1,000 \mathrm{pg} / \mathrm{ml}$. Although the statistical differences were not significant (aOR $(95 \% \mathrm{Cl}): 0.90(0.76,1.05)$ for clinical pregnancy rate, and $0.88(0.75,1.03)$ for live birth rate). The result indicated that $\geq 5000 \mathrm{pg} / \mathrm{ml}$ might comprise the pregnancy outcomes in fresh embryo transfer cycle, which was consistent with those in previous reports $[15,25]$. However, a single-center study of 3,393 fresh cycles revealed that the clinical live birth rate and live birth rate were higher in the high E2 groups ( $\geq 3,757 \mathrm{pg} / \mathrm{ml}$ ). This result might be biased, because the younger age in the high E2 group was not adjusted.

The receptivity of the endometrium is critical to the implantation of embryos. When the embryos are transferred in fresh, the status of the high E2 level maintain to 7-8 gestational weeks, and the serum E2 levels become comparable to the natural conception [4]. The in vitro experiments revealed that the attachment between receptive-phase endometrial epithelial cells and human choriocarcinoma cells decreased after exposure to higher concentrations of E2. The other study also revealed the altered expression of proteins related to endometrium receptivity and its regulating pathways when the E2 level was increased [26]. Thus, in fresh cycles, when E2 on trigger day is higher than $5,000 \mathrm{pg} / \mathrm{ml}$, the decrease in endometrium receptivity might lead to limited decrease of pregnancy and live birth rates.

The present study is the first to show that the live birth rates for FET cycles are positively correlated to the E2 level on trigger day. Two previous studies (403 and 755 cycles) reported that the E2 on trigger day was irrelevant to the clinical pregnancy rates in the subsequent FET cycles, while the live birth rates were not reported $[15,16]$. Another single-center study conducted by Duan (10581 cycles) indicated the high E2 levels during COS is correlated to the decrease in clinical pregnancy and live birth rates [11]. When E2 is $<2,724.8 \mathrm{pg} / \mathrm{ml}, \mathrm{within} 2,724.8-$ $4,087.2 \mathrm{pg} / \mathrm{ml}$, and $>4,087.2 \mathrm{pg} / \mathrm{ml}$ on trigger day, the live birth rates were $28.80 \%, 26.90 \%$ and $25.99 \%$, respectively [11]. These were close to each other, but the difference was significant. The OR and aOR were not reported in the study. Hence, the impact of E2 on live birth rates could not be accurately assessed. Furthermore, the live birth rates reported in that study were much lower than those in the present study (45.4\%) and other research (which were within 35.6\%-45.6\% [27-30]). Consequently, other factors, except for the E2 on trigger day, might interfere with the live birth rates for FET cycles in the study conducted by Duan.

When the frozen-thawed embryos are transferred to uterine, the elevated serum E2 brought by COS returns to normal level, and the endometrium is not exposed to the supraphysiological E2, indicating that the receptivity may not be impaired. The decrease in live birth rates for the lower E2 groups may have resulted from the high proportion of small follicles in the lower E2 groups. It was reported that the mature oocytes retrieved from non-dominant small follicles yielded lower live birth rates, when compared to that of oocytes retrieved from large dominant follicles [31].

The present data also shows that the CLBR is correlated to the E2 level on trigger day in a segmented manner, after adjusting the confounders (the oocytes retrieved are included). Zhang [20] reported the smooth fitting curve for the CLBR and E2 of 1,141 patients with a similar pattern, while the multivariate analysis did not reveal statistically significant differences among the different E2 groups. In the study conducted by Zhang, the number of complete cycles with E2 $>6,000 \mathrm{pg} / \mathrm{ml}$ was limited. Consequently, the relationship between the CLBR and extremely high E2 (>6,000 pg/ml) might be inconsistent from the actual situation. Hence, the present analysis of the large data may be more reliable.

There are some limitations in the present study. First, the retrospective design makes it inevitable for the missing values and outliers. Hence, the investigators adopted the multivariable analysis for the data using multiple imputations. In addition, there are two assays for the serum E2 test, and the measurements may be inconsistent. Moreover, the details for the COS regimens and embryo culture in the five reproductive centers may be different. However, the GLIMMIX and multi-level models allow for the analysis in this condition [32].

The most distinctive advantage of the present study is the large data obtained from five reproductive centers in different regions of China. The multicenter study can reach representative and persuasive conclusions. Furthermore, the investigators are the first to evaluate the overall 
steps of the development of preimplantation embryos, the pregnancy outcomes (biochemical pregnancy, clinical pregnancy, and live birth) in both fresh embryo transfer and FET cycles, and the CLBR in complete cycle in the same cohort.

\section{Conclusion}

In summary, high levels of E2 on trigger day is associated with decreased rates of properly developed embryos. In fresh embryo cycles, live birth rates is not significantly impaired in elevated E2 cycles. The live birth rate for FET cycles is positively correlated to the E2 level on trigger day. The CLBR is positively associated with E2 on trigger day when E2 $<14,000 \mathrm{pg} / \mathrm{ml}$. Otherwise, E2 was irrelevant to CLBR.

\section{Abbreviations}

E2: estradiol

COS: controlled ovarian stimulation

FET: frozen-thawed embryo transfer

CLBR: cumulative live birth rates

IVF: in vitro fertilization

ICSI: intracytoplasmic sperm injection

aOR: adjusted odds ratio

Cl: confidence interval

GnRH-a: gonadotropin-releasing hormone agonist

GnRH-ant: GnRH antagonist

PPOS: progestin primed ovarian stimulation

HCG: human chorionic gonadotrophin

HRT: hormone replacement therapy

GLIMMIX: generalized linear mixed

BMI: body mass index

FSH: follicle-stimulating hormone

LH: luteinizing hormone

aMD: adjusted mean difference

\section{Declarations}

Ethics approval and consent to participate This study was reviewed and approved by the Ethics Committees at the Sixth Affiliated Hospital of Sun Yat-sen University (2020ZSLYEC-295), Tongji Hospital of Tongji Medical College of Huazhong University of Science and Technology (TJIRB20210320), Northwest Women's and Children's Hospital (2019013), Henan Provincial People's Hospital (SYSZ-LL-2019110401), and Jiangsu Provincial Hospital (2020-SR-046). The written informed consent was waived by the ethics committees because of the retrospective nature of the study.

Consent for publication Not appliable.

Availability of data and materials The datasets used and/or analyzed during the current study are available from the corresponding author on reasonable request.

Competing interests The authors declare that they have no competing interests. 
Funding This work was supported by the National Key Research and Development Program of China (2017YFC1001603) and the National Natural Science Foundation of China (82071713). The funding sources were not involved in study design.

Author contributions L.J., J-Z.S, Y-D.M., C-L.Z., R.H. collected the data. M.W. and X-Y.L. were involved in study design. M.W. performed the statistical analysis and drafted the article. X-Y.L. interpreted the data. All authors participated to the discussion of the findings and revised the article.

Acknowledgements Not applicable.

\section{References}

1. Law YJ, Zhang N, Venetis CA, Chambers GM, Harris K. The number of oocytes associated with maximum cumulative live birth rates per aspiration depends on female age: a population study of 221221 treatment cycles. Hum Reprod. 2019;34:1778-87.

2. Mitwally MF, Bhakoo HS, Crickard K, Sullivan MW, Batt RE, Yeh J. Estradiol production during controlled ovarian hyperstimulation correlates with treatment outcome in women undergoing in vitro fertilization-embryo transfer. Fertil Steril. 2006;86:588-96.

3. Ketha H, Girtman A, Singh RJ. Estradiol assays-The path ahead. Steroids. 2015;99:39-44.

4. Jarvela IY, Pelkonen S, Uimari O, Makikallio K, Puukka K, Ruokonen A, Tekay A, Martikainen H. Controlled ovarian hyperstimulation leads to high progesterone and estradiol levels during early pregnancy. Hum Reprod. 2014;29:2393-401.

5. Ma W-g, Song H, Das SK, Paria BC, Dey SK. Estrogen is a critical determinant that specifies the duration of the window of uterine receptivity for implantation. Proc Natl Acad Sci U S A. 2003;100:2963-8.

6. Li L, Wang P, Liu S, Bai X, Zou B, Li Y. Transcriptome sequencing of endometrium revealed alterations in mRNAs and IncRNAs after ovarian stimulation. J Assist Reprod Genet. 2020;37:21-32.

7. Steward RG, Zhang CE, Shah AA, Yeh JS, Chen C, Li YJ, Price TM, Muasher SJ. High Peak Estradiol Predicts Higher Miscarriage and Lower Live Birth Rates in High Responders Triggered with a GnRH Agonist in IVF/ICSI Cycles. J Reprod Med. 2015;60:463-70.

8. Senapati S, Wang F, Ord T, Coutifaris C, Feng R, Mainigi M. Superovulation alters the expression of endometrial genes critical to tissue remodeling and placentation. J Assist Reprod Genet. 2018;35:1799-808.

9. Wittemer C, Ohl J, Bettahar-Lebugle K, Viville S, Nisand I. A quantitative and morphological analysis of oocytes collected during 438 IVF cycles. J Assist Reprod Genet. 2000;17:44-50.

10. Valbuena D, Martin J, de Pablo JL, Remohí J, Pellicer A, Simón C. Increasing levels of estradiol are deleterious to embryonic implantation because they directly affect the embryo. Fertil Steril. 2001;76:962-8.

11. Duan CC, Li C, He YC, Xu JJ, Shi CY, Hu HT, et al. Oocyte exposure to supraphysiological estradiol during ovarian stimulation increased the risk of adverse perinatal outcomes after frozen-thawed embryo transfer: a retrospective cohort study. J Dev Orig Health Dis 2019:111.

12. Imudia AN, Goldman RH, Awonuga AO, Wright DL, Styer AK, Toth TL. The impact of supraphysiologic serum estradiol levels on periimplantation embryo development and early pregnancy outcome following in vitro fertilization cycles. J Assist Reprod Genet. 2014;31:65-71.

13. Peña JE, Chang PL, Chan L-K, Zeitoun K, Thornton MH, Sauer MV. Supraphysiological estradiol levels do not affect oocyte and embryo quality in oocyte donation cycles. Human reproduction (Oxford England). 2002;17:83-7.

14. Bianco K, Mahutte NG, Arici A, Sakkas D, Taylor HS. Effect of estradiol on oocyte development. Int J Gynaecol Obstet. 2009;104:230-2.

15. Yu Ng EH, Yeung WS, Yee Lan Lau E, So WW, Ho PC. High serum oestradiol concentrations in fresh IVF cycles do not impair implantation and pregnancy rates in subsequent frozen-thawed embryo transfer cycles. Hum Reprod. 2000;15:250-5.

16. Wu Z, Li R, Ma Y, Deng B, Zhang X, Meng Y, Chen X, Liu P, Qiao J. Effect of HCG-day serum progesterone and oestradiol concentrations on pregnancy outcomes in GnRH agonist cycles. Reprod Biomed Online. 2012;24:511-20.

17. Kara M, Kutlu T, Sofuoglu K, Devranoglu B, Cetinkaya T. Association between serum estradiol level on the hCG administration day and IVF-ICSI outcome. Iranian journal of reproductive medicine. 2012;10:53-8.

18. Foroozanfard F, Moraveji SA, Taghavi SA, Karimi F. Association Between Serum Estradiol Level on the Day of hCG Administration and IVF-ICSI Outcome. J Obstet Gynaecol India. 2016;66:170-3.

19. Wang M, Hao C, Bao H, Huang X, Liu Z, Zhang W, Li F. Effect of elevated estradiol levels on the hCG administration day on IVF pregnancy and birth outcomes in the long GnRH-agonist protocol: analysis of 3393 cycles. Arch Gynecol Obstet. 2017;295:407-14.

20. Zhang W, Tian Y, Xie D, Miao Y, Liu J, Wang X. The impact of peak estradiol during controlled ovarian stimulation on the cumulative live birth rate of IVF/ICSI in non-PCOS patients. J Assist Reprod Genet. 2019;36:2333-44. 
21. Huang J, Lu X, Lin J, Chen Q, Gao H, Lyu Q, Cai R, Kuang Y. Association between peak serum estradiol level during controlled ovarian stimulation and neonatal birthweight in freeze-all cycles: a retrospective study of 8501 singleton live births. Hum Reprod. 2020;35:42433.

22. Alpha Scientists in Reproductive M, Embryology ESIGo. The Istanbul consensus workshop on embryo assessment: proceedings of an expert meeting. Hum Reprod 2011; 26:1270-1283.

23. Gardner DK, Lane M, Stevens J, Schlenker T, Schoolcraft WB. Blastocyst score affects implantation and pregnancy outcome: towards a single blastocyst transfer. Fertil Steril. 2000;73:1155-8.

24. Silber SJ, Kato K, Aoyama N, Yabuuchi A, Skaletsky H, Fan Y, Shinohara K, Yatabe N, Kobayashi T. Intrinsic fertility of human oocytes. Fertil Steril. 2017;107:1232-7.

25. Li X, Zeng C, Shang J, Wang S, Gao X-L, Xue Q. Association between serum estradiol level on the human chorionic gonadotrophin administration day and clinical outcome. Chin Med J. 2019;132:1194-201.

26. Ullah K, Rahman TU, Pan HT, Guo MX, Dong XY, Liu J, et al. Serum estradiol levels in controlled ovarian stimulation directly affect the endometrium. J Mol Endocrinol. 2017;59:105-19.

27. Tao Y, Wang N. Adjuvant Vaginal Use of Sildenafil Citrate in a Hormone Replacement Cycle Improved Live Birth Rates Among 10,069 Women During First Frozen Embryo Transfers. Drug Des Devel Ther. 2020;14:5289-97.

28. Du Y, Yan L, Sun M, Sheng Y, Li X, Feng Z, Tang R. Effect of Human Chorionic Gonadotropin Injection Before Frozen Embryo Transfer on Pregnancy Outcomes in Endometriosis-Associated Infertility. Front Med (Lausanne) 2020; 7:592921.

29. Liu Y, Wu Y. Progesterone Intramuscularly or Vaginally Administration May Not Change Live Birth Rate or Neonatal Outcomes in Artificial Frozen-Thawed Embryo Transfer Cycles. Front Endocrinol (Lausanne). 2020;11:539427.

30. Huang J, Lin J, Cai R, Lu X, Song N, Gao H, Kuang Y. Significance of endometrial thickness change after human chorionic gonadotrophin triggering in modified natural cycles for frozen-thawed embryo transfer. Ann Transl Med 2020; 8:1590.

31. Teramoto S, Osada H, Sato Y, Shozu M. Nondominant small follicles are a promising source of mature oocytes in modified natural cycle in vitro fertilization and embryo transfer. Fertil Steril. 2016;106:113-8.

32. Hirst WM, Vail A, Brison DR, Roberts SA. Prognostic factors influencing fresh and frozen IVF outcomes: an analysis of the UK national database. Reprod Biomed Online. 2011;22:437-48.

\section{Tables}

Table 2 Embryo developments for groups stratified by estradiol (E2) on trigger day

\begin{tabular}{|c|c|c|c|c|c|c|c|c|}
\hline \multirow[t]{2}{*}{$\begin{array}{l}\text { E2 on trigger day } \\
(\mathrm{pg} / \mathrm{ml})\end{array}$} & \multicolumn{2}{|c|}{ IVF fertilization rates } & \multicolumn{2}{|c|}{ ICSI fertilization rates } & \multicolumn{2}{|l|}{ Cleavage rates } & \multicolumn{2}{|c|}{$\begin{array}{l}\text { Specific stage embryos } \\
\text { rates }\end{array}$} \\
\hline & *aMD $(95 \% \mathrm{Cl})$ & $p$ & *aMD (95\% Cl) & $p$ & *aMD (95\% Cl) & $p$ & *aMD (95\% Cl) & $p$ \\
\hline$<1000$ & Reference & & Reference & & Reference & & Reference & \\
\hline $1,000-2,000$ & $\begin{array}{l}-0.03(-0.03 \\
-0.02)\end{array}$ & $<0.01$ & $\begin{array}{l}-0.03(-0.05 \\
-0.02)\end{array}$ & $<0.01$ & $\begin{array}{l}-0.002(-0.004 \\
0.001)\end{array}$ & 0.16 & $\begin{array}{l}-0.10(-0.11 \\
-0.10)\end{array}$ & $<0.01$ \\
\hline $2,000-3,000$ & $\begin{array}{l}-0.03(-0.04 \\
-0.02)\end{array}$ & $<0.01$ & $\begin{array}{l}-0.04(-0.06 \\
-0.03)\end{array}$ & $<0.01$ & $\begin{array}{l}-0.002(-0.005 \\
0.001)\end{array}$ & 0.12 & $\begin{array}{l}-0.13(-0.14 \\
-0.12)\end{array}$ & $<0.01$ \\
\hline $3,000-4,000$ & $\begin{array}{l}-0.03(-0.04 \\
-0.02)\end{array}$ & $<0.01$ & $\begin{array}{l}-0.04(-0.06 \\
-0.03)\end{array}$ & $<0.01$ & $\begin{array}{l}-0.000(-0.003 \\
0.003)\end{array}$ & 0.88 & $\begin{array}{l}-0.14(-0.15 \\
-0.13)\end{array}$ & $<0.01$ \\
\hline $4,000-5,000$ & $\begin{array}{l}-0.02(-0.03 \\
-0.02)\end{array}$ & $<0.01$ & $\begin{array}{l}-0.03(-0.05 \\
-0.01)\end{array}$ & $<0.01$ & $\begin{array}{l}-0.001(-0.004 \\
0.002)\end{array}$ & 0.40 & $\begin{array}{l}-0.15(-0.16 \\
-0.15)\end{array}$ & $<0.01$ \\
\hline$\geq 5,000$ & $\begin{array}{l}-0.02(-0.03 \\
-0.01)\end{array}$ & $<0.01$ & $\begin{array}{l}-0.04(-0.06 \\
-0.02)\end{array}$ & $<0.01$ & $\begin{array}{l}-0.001(-0.004 \\
0.002)\end{array}$ & 0.40 & $\begin{array}{l}-0.14(-0.15 \\
-0.13)\end{array}$ & $<0.01$ \\
\hline
\end{tabular}

*Adjusted with the maternal age at oocyte retrieval, body mass index, paternal age at oocyte retrieval, infertility type, infertility duration, infertility indications, antral follicle count, basal level of follicle-stimulating hormone, basal level of luteinizing hormone, controlled ovarian stimulation regimens, stimulation duration, total gonadotropin dose, LH on trigger day, progesterone on trigger day, fertilization method, and reproductive centers. Multiplicity was adjusted with Dunnett's test. Bold and italic: $P<0.05$, statistically significant. IVF, in vitro fertilization; ICSI, intracytoplasmic sperm injection; aMD, adjusted mean difference; Cl, confidence interval.

Table 3 Characteristics of fresh embryo transfer cycles 


\begin{tabular}{|c|c|c|c|c|c|c|c|}
\hline \multirow[t]{3}{*}{ Factors } & \multicolumn{7}{|c|}{ E2 on trigger day $(\mathrm{pg} / \mathrm{ml})$} \\
\hline & $<1000$ & $1000-2000$ & $2000-3000$ & $3000-4000$ & $4000-5000$ & $\geq 5000$ & $p$ \\
\hline & $(N=5907)$ & $(N=12103)$ & $(N=10814)$ & $(N=7194)$ & $(N=4718)$ & $(N=5116)$ & \\
\hline Maternal age (years) & $34.8 \pm 5.5$ & $32.1 \pm 4.9$ & $31.1 \pm 4.5$ & $30.5 \pm 4.3$ & $30.1 \pm 4.1$ & $30.0 \pm 4.0$ & $<0.001^{a}$ \\
\hline Maternal BMI (kg/m²) & $23.4 \pm 3.4$ & $23.0 \pm 3.2$ & $22.4 \pm 3.2$ & $22.1 \pm 3.0$ & $21.9 \pm 3.0$ & $21.6 \pm 2.9$ & $<0.001^{a}$ \\
\hline Infertility indications & & & & & & & $<0.001^{b}$ \\
\hline Male factors & $342(6.5)$ & $1276(11.9)$ & $1380(14.0)$ & $1022(15.5)$ & 759 (17.2) & $844(17.1)$ & \\
\hline Ovarian factor & $\begin{array}{l}2274 \\
(43.0)\end{array}$ & 1689 (15.7) & $651(6.6)$ & $238(3.6)$ & $95(2.2)$ & $57(1.2)$ & \\
\hline Endometriosis & $298(5.6)$ & $688(6.4)$ & $692(7.0)$ & $473(7.2)$ & $282(6.4)$ & $243(4.9)$ & \\
\hline Ovulatory disorders & $524(9.9)$ & $1581(14.7)$ & $1427(14.5)$ & $917(13.9)$ & $582(13.2)$ & $654(13.2)$ & \\
\hline Pelvic/tubal factor & $\begin{array}{l}1668 \\
(31.5)\end{array}$ & $4913(45.6)$ & $5074(51.5)$ & 3470 (52.7) & $2384(54.0)$ & $2818(57.0)$ & \\
\hline Others & $183(3.5)$ & $618(5.7)$ & $619(6.3)$ & $466(7.1)$ & $314(7.1)$ & $332(6.7)$ & \\
\hline Antral follicle counts & $8.4 \pm 5.7$ & $11.5 \pm 6.3$ & $13.0 \pm 6.0$ & $13.9 \pm 5.7$ & $14.4 \pm 5.5$ & $14.7 \pm 5.3$ & $<0.001^{a}$ \\
\hline Basal FSH (IU/L) & $\begin{array}{l}7.9(6.4 \\
10.1)\end{array}$ & $7.1(6.0,8.6)$ & $6.9(5.9,8.1)$ & $6.9(5.8,8.0)$ & $6.8(5.9,8.0)$ & $6.7(5.7,7.8)$ & $<0.001^{c}$ \\
\hline COS protocols & & & & & & & $<0.001^{b}$ \\
\hline GnRH-a based & $\begin{array}{l}2441 \\
(44.7)\end{array}$ & 8638 (72.7) & 8476 (79.9) & $5796(82.6)$ & $4011(87.1)$ & $4638(93.1)$ & \\
\hline GnRH-ant based & $\begin{array}{l}1127 \\
(20.6)\end{array}$ & $2781(23.4)$ & $1855(17.5)$ & $1045(14.9)$ & $473(10.3)$ & $303(6.1)$ & \\
\hline Mild stimulation & $\begin{array}{l}1545 \\
(28.3)\end{array}$ & $461(3.9)$ & $268(2.5)$ & $171(2.4)$ & $120(2.6)$ & $40(0.80)$ & \\
\hline Natural cycle & $348(6.4)$ & $8(0.07)$ & $3(0.03)$ & $4(0.06)$ & $2(0.04)$ & $2(0.04)$ & \\
\hline E2 on trigger day $(\mathrm{pg} / \mathrm{ml})$ & $\begin{array}{l}631.0 \\
(377.0 \\
832.0)\end{array}$ & $\begin{array}{l}1527.0 \\
(1281.0 \\
1757.0)\end{array}$ & $\begin{array}{l}2455.0 \\
(2217.0 \\
2719.0)\end{array}$ & $\begin{array}{l}3405.0 \\
(3151.0 \\
3679.0)\end{array}$ & $\begin{array}{l}4406.0 \\
(4225.0 \\
4726.0)\end{array}$ & $\begin{array}{l}6131.5 \\
(5479.0 \\
7150.5)\end{array}$ & $<0.001^{c}$ \\
\hline $\begin{array}{l}\text { Endometrium thickness } \\
\text { on trigger day }(\mathrm{mm})\end{array}$ & $10.0 \pm 2.5$ & $11.5 \pm 7.5$ & $11.6 \pm 3.7$ & $11.5 \pm 2.7$ & $11.5 \pm 3.4$ & $11.7 \pm 3.5$ & $<0.001^{a}$ \\
\hline Oocytes retrieved & $3.3 \pm 2.6$ & $7.2 \pm 3.5$ & $9.6 \pm 3.8$ & $10.9 \pm 3.9$ & $11.5 \pm 3.9$ & $13.2 \pm 3.9$ & $<0.001^{a}$ \\
\hline $\begin{array}{l}\text { Number of embryos } \\
\text { transferred }\end{array}$ & & & & & & & $<0.001^{b}$ \\
\hline 1 & $\begin{array}{l}3156 \\
(53.4)\end{array}$ & $3662(30.3)$ & $2841(26.3)$ & $1983(27.6)$ & $1465(31.1)$ & $1891(37.0)$ & \\
\hline$\geq 2$ & $\begin{array}{l}2749 \\
(46.6)\end{array}$ & $8436(69.7)$ & 7971 (73.7) & $5207(72.4)$ & 3247 (68.9) & $3224(63.0)$ & \\
\hline $\begin{array}{l}\text { Stage of embryos at } \\
\text { transferring }\end{array}$ & & & & & & & $<0.001^{b}$ \\
\hline day 3 & $\begin{array}{l}5531 \\
(93.6)\end{array}$ & $10808(89.3)$ & 9051 (83.7) & $5771(80.2)$ & 3589 (76.1) & $2993(58.5)$ & \\
\hline day 5 & $273(4.6)$ & $1178(9.7)$ & $1631(15.1)$ & $1336(18.6)$ & $1052(22.3)$ & $1967(38.4)$ & \\
\hline day 6 & $60(1.0)$ & $24(0.20)$ & $21(0.19)$ & $12(0.17)$ & $4(0.08)$ & $3(0.06)$ & \\
\hline unknown & $16(0.27)$ & $68(0.56)$ & $97(0.90)$ & $65(0.90)$ & $69(1.5)$ & $145(2.8)$ & \\
\hline others & $27(0.46)$ & $25(0.21)$ & $14(0.13)$ & $10(0.14)$ & $4(0.08)$ & $8(0.16)$ & \\
\hline
\end{tabular}




\begin{tabular}{|c|c|c|c|c|c|c|c|}
\hline \multirow[t]{3}{*}{ Factors } & \multicolumn{7}{|c|}{ E2 on trigger day $(\mathrm{pg} / \mathrm{ml})$} \\
\hline & $<1000$ & $1000-2000$ & $2000-3000$ & $3000-4000$ & $4000-5000$ & $\geq 5000$ & $p$ \\
\hline & $(\mathrm{N}=5907)$ & $(N=12103)$ & $(\mathrm{N}=10814)$ & $(\mathrm{N}=7194)$ & $(N=4718)$ & $(N=5116)$ & \\
\hline $\begin{array}{l}\text { Quality of embryos } \\
\text { transferred }\end{array}$ & & & & & & & $<0.001^{b}$ \\
\hline not good & $\begin{array}{l}1391 \\
(24.5)\end{array}$ & $2396(21.9)$ & $1953(19.5)$ & $1347(20.0)$ & $910(20.2)$ & $1442(28.9)$ & \\
\hline others & $43(0.76)$ & $89(0.81)$ & $107(1.1)$ & $77(1.1)$ & $70(1.6)$ & $156(3.1)$ & \\
\hline good & $\begin{array}{l}4234 \\
(74.7)\end{array}$ & 8465 (77.3) & $7952(79.4)$ & $5298(78.8)$ & $3536(78.3)$ & $3396(68.0)$ & \\
\hline Biochemical pregnancy & & & & & & & $<0.001^{b}$ \\
\hline No & $\begin{array}{l}3356 \\
(56.8)\end{array}$ & $5197(42.9)$ & 4019 (37.2) & $2620(36.4)$ & $1652(35.0)$ & $1801(35.2)$ & \\
\hline Yes & $\begin{array}{l}2551 \\
(43.2)\end{array}$ & $6906(57.1)$ & $6795(62.8)$ & $4574(63.6)$ & $3066(65.0)$ & $3315(64.8)$ & \\
\hline Clinical pregnancy & & & & & & & $<0.001^{b}$ \\
\hline No & $\begin{array}{l}3599 \\
(60.9)\end{array}$ & $5602(46.3)$ & 4405 (40.7) & $2896(40.3)$ & 1805 (38.3) & 2035 (39.8) & \\
\hline Yes & $\begin{array}{l}2308 \\
(39.1)\end{array}$ & $6501(53.7)$ & 6409 (59.3) & $4298(59.7)$ & $2913(61.7)$ & $3081(60.2)$ & \\
\hline Live birth & & & & & & & $<0.001^{b}$ \\
\hline No & $\begin{array}{l}4090 \\
(69.2)\end{array}$ & $6720(55.5)$ & $5437(50.3)$ & $3514(48.8)$ & $2228(47.2)$ & $2478(48.4)$ & \\
\hline Yes & $\begin{array}{l}1817 \\
(30.8)\end{array}$ & $5383(44.5)$ & $5377(49.7)$ & $3680(51.2)$ & $2490(52.8)$ & $2638(51.6)$ & \\
\hline
\end{tabular}

${ }^{a}$ Continuous data following normal distribution are described with mean \pm standard deviation, compared by ANOVA test; ${ }^{b}$ Categorical data are described with number (percentage), compared by Pearson's chi-square test; ${ }^{c}$ Continuous data which don't follow normal distribution are described with median (quartiles), compared by Kruskal-Wallis test. Bold and italic: $p<0.05$, statistically significant. BMI, body mass index; FSH, follicle-stimulating hormone; E2, estradiol; COS, controlled ovarian stimulation; $\mathrm{GnRH}$-a, gonadotropin-releasing hormone agonist; $\mathrm{GnRH}$ ant, gonadotropin-releasing hormone antagonist; Number of missing data $\mathbb{m}$ maternal age $=1$, maternal BMI $=496$, infertility indication $=4005$, antral follicle counts $=1986$, basal FSH $=2318$, COS protocols $=1296$, endometrium thickness on trigger day $=292$; number of embryos transferred $=20$; developing days of embryos at transferring $=549$; quality of embryos transferred $=2990$.

Table 4 Characteristics of frozen-thawed embryo transfer (FET) cycles 


\begin{tabular}{|c|c|c|c|c|c|c|c|}
\hline \multirow[t]{2}{*}{ Factors } & \multicolumn{7}{|c|}{ E2 on trigger day $(\mathrm{pg} / \mathrm{ml})$} \\
\hline & $\begin{array}{l}<1000 \\
(N=5397)\end{array}$ & $\begin{array}{l}1000-2000 \\
(\mathrm{~N}=9955)\end{array}$ & $\begin{array}{l}2000-3000 \\
(\mathrm{~N}=9516)\end{array}$ & $\begin{array}{l}3000-4000 \\
(\mathrm{~N}=8208)\end{array}$ & $\begin{array}{l}4000-5000 \\
(\mathrm{~N}=6976)\end{array}$ & $\begin{array}{l}\geq 5000 \\
(N=16708)\end{array}$ & $p$ \\
\hline Maternal age at FET (years) & $36.3 \pm 5.7$ & $34.1 \pm 5.4$ & $32.3 \pm 4.9$ & $31.3 \pm 4.5$ & $30.8 \pm 4.4$ & $30.3 \pm 4.1$ & $<0.001^{a}$ \\
\hline $\begin{array}{l}\text { Maternal age at oocyte } \\
\text { retrieval (years) }\end{array}$ & $36.0 \pm 5.7$ & $33.7 \pm 5.4$ & $31.8 \pm 4.9$ & $30.8 \pm 4.5$ & $30.3 \pm 4.4$ & $29.7 \pm 4.0$ & $<0.001^{a}$ \\
\hline Infertility indications & & & & & & & $<0.001^{b}$ \\
\hline Male factors & $248(5.2)$ & $771(8.5)$ & $918(10.4)$ & $955(12.5)$ & $925(14.1)$ & $2208(13.8)$ & \\
\hline Ovarian factor & $\begin{array}{l}2627 \\
(55.1)\end{array}$ & $2703(29.8)$ & $1219(13.8)$ & $530(6.9)$ & $331(5.0)$ & $252(1.6)$ & \\
\hline Endometriosis & $267(5.6)$ & $606(6.7)$ & $675(7.7)$ & $602(7.9)$ & $523(8.0)$ & $1210(7.6)$ & \\
\hline Ovulatory disorders & $276(5.8)$ & $1037(11.4)$ & $1306(14.8)$ & $1271(16.6)$ & $1129(17.2)$ & 3451 (21.5) & \\
\hline Pelvic/tubal factor & $\begin{array}{l}1179 \\
(24.7)\end{array}$ & $3502(38.6)$ & $4233(48.0)$ & 3790 (49.5) & $3200(48.7)$ & 7953 (49.6) & \\
\hline Others & 175 (3.7) & $453(5.0)$ & $470(5.3)$ & $516(6.7)$ & $460(7.0)$ & $948(5.9)$ & \\
\hline Antral follicle counts & $7.0 \pm 5.2$ & $10.3 \pm 6.4$ & $13.2 \pm 6.8$ & $14.6 \pm 6.5$ & $15.6 \pm 6.4$ & $17.1 \pm 6.5$ & $<0.001^{a}$ \\
\hline Basal FSH (IU/L) & $\begin{array}{l}8.4(6.7 \\
11.2)\end{array}$ & $7.4(6.1,9.2)$ & $6.9(5.8,8.3)$ & $6.7(5.7,7.9)$ & $6.7(5.7,7.9)$ & $6.4(5.4,7.5)$ & $<0.001^{c}$ \\
\hline COS protocols & & & & & & & $<0.001^{b}$ \\
\hline GnRH-a based & $930(20.7)$ & $3648(40.5)$ & $4920(54.0)$ & $4912(61.8)$ & $3789(55.8)$ & $11778(72.2)$ & \\
\hline GnRH-ant based & $946(21.1)$ & $2759(30.7)$ & $2580(28.3)$ & $1884(23.7)$ & $1815(26.7)$ & $3304(20.3)$ & \\
\hline PPOS & $751(16.8)$ & $548(6.1)$ & $196(2.2)$ & $105(1.3)$ & $45(0.66)$ & $58(0.36)$ & \\
\hline Mild stimulation & $\begin{array}{l}1754 \\
(39.1)\end{array}$ & $2038(22.6)$ & $1416(15.5)$ & $1042(13.1)$ & $1141(16.8)$ & $1159(7.1)$ & \\
\hline Natural cycle & $101(2.3)$ & $7(0.08)$ & $0(0.0)$ & $2(0.03)$ & $4(0.06)$ & $3(0.02)$ & \\
\hline $\begin{array}{l}\text { Endometrial preparation } \\
\text { regimens }\end{array}$ & & & & & & & $<0.001^{b}$ \\
\hline $\begin{array}{l}\text { Hormone replacement } \\
\text { therapy }\end{array}$ & $\begin{array}{l}2813 \\
(53.2)\end{array}$ & $5563(56.9)$ & $5221(55.7)$ & $4535(56.1)$ & $3098(45.0)$ & $9113(55.5)$ & \\
\hline Stimulation protocol & $673(12.7)$ & $1300(13.3)$ & $1607(17.2)$ & $1443(17.9)$ & $1612(23.4)$ & 3259 (19.9) & \\
\hline Down-regulation protocol & $616(11.6)$ & $1336(13.7)$ & $1311(14.0)$ & $996(12.3)$ & $833(12.1)$ & 1995 (12.2) & \\
\hline Natural cycle & $\begin{array}{l}1190 \\
(22.5)\end{array}$ & $1586(16.2)$ & $1227(13.1)$ & $1104(13.7)$ & $1334(19.4)$ & $2050(12.5)$ & \\
\hline E2 on trigger day $(\mathrm{pg} / \mathrm{ml})$ & $\begin{array}{l}660.2 \\
(432.0 \\
834.0)\end{array}$ & $\begin{array}{l}1501.0 \\
(1258.0, \\
1748.0)\end{array}$ & $\begin{array}{l}2486.0 \\
(2246.0 \\
2739.0)\end{array}$ & $\begin{array}{l}3394.0 \\
(3112.0 \\
3683.0)\end{array}$ & $\begin{array}{l}4540.0 \\
(4260.0 \\
4811.5)\end{array}$ & $\begin{array}{l}6885.0 \\
(5830.0 \\
8424.0)\end{array}$ & $<0.001^{c}$ \\
\hline $\begin{array}{l}\text { Endometrium thickness on } \\
\text { transformation day }(\mathrm{mm})\end{array}$ & $9.8 \pm 2.4$ & $9.9 \pm 1.9$ & $10.0 \pm 1.9$ & $10.0 \pm 1.8$ & $10.0 \pm 1.7$ & $10.0 \pm 1.7$ & $<0.001^{a}$ \\
\hline $\begin{array}{l}\text { Number of embryos } \\
\text { transferred }\end{array}$ & & & & & & & $<0.001^{b}$ \\
\hline 1 & $\begin{array}{l}3046 \\
(56.4)\end{array}$ & $4546(45.7)$ & $4178(43.9)$ & 3489 (42.5) & 3215 (46.1) & $6898(41.3)$ & \\
\hline$\geq 2$ & $\begin{array}{l}2350 \\
(43.6)\end{array}$ & $5409(54.3)$ & $5337(56.1)$ & 4719 (57.5) & 3761 (53.9) & $9810(58.7)$ & \\
\hline $\begin{array}{l}\text { Stage of embryos at } \\
\text { transferring }\end{array}$ & & & & & & & $<0.001^{b}$ \\
\hline
\end{tabular}




\begin{tabular}{|c|c|c|c|c|c|c|c|}
\hline \multirow[t]{3}{*}{ Factors } & \multicolumn{7}{|c|}{ E2 on trigger day $(\mathrm{pg} / \mathrm{ml})$} \\
\hline & $<1000$ & $1000-2000$ & $2000-3000$ & $3000-4000$ & $4000-5000$ & $\geq 5000$ & $p$ \\
\hline & $(\mathrm{N}=5397)$ & $(\mathrm{N}=9955)$ & $(\mathrm{N}=9516)$ & $(\mathrm{N}=8208)$ & $(\mathrm{N}=6976)$ & $(\mathrm{N}=16708)$ & \\
\hline day 3 & $\begin{array}{l}2634 \\
(48.8)\end{array}$ & 3707 (37.2) & $2304(24.2)$ & $1642(20.0)$ & $927(13.3)$ & $2541(15.2)$ & \\
\hline day 5 & $774(14.3)$ & $2507(25.2)$ & $3556(37.4)$ & $3389(41.3)$ & $3101(44.5)$ & $9043(54.1)$ & \\
\hline day 6 & $496(9.2)$ & $1555(15.6)$ & $1766(18.6)$ & $1542(18.8)$ & $963(13.8)$ & $2381(14.3)$ & \\
\hline unknown & $31(0.57)$ & $71(0.71)$ & $92(0.97)$ & $75(0.91)$ & $83(1.2)$ & $284(1.7)$ & \\
\hline others & $\begin{array}{l}1462 \\
(27.1)\end{array}$ & 2115 (21.2) & $1798(18.9)$ & $1560(19.0)$ & $1902(27.3)$ & $2459(14.7)$ & \\
\hline $\begin{array}{l}\text { Quality of embryos } \\
\text { transferred }\end{array}$ & & & & & & & $<0.001^{b}$ \\
\hline not good & $\begin{array}{l}1190 \\
(23.7)\end{array}$ & $2348(26.0)$ & $2089(23.8)$ & $1634(21.5)$ & $1494(22.4)$ & 3977 (24.6) & \\
\hline others & $\begin{array}{l}1489 \\
(29.6)\end{array}$ & $2178(24.1)$ & $1879(21.4)$ & $1637(21.5)$ & $1982(29.7)$ & $2740(17.0)$ & \\
\hline good & $\begin{array}{l}2346 \\
(46.7)\end{array}$ & $4522(50.0)$ & $4814(54.8)$ & $4346(57.1)$ & 3196 (47.9) & $9446(58.4)$ & \\
\hline Biochemical pregnancy & & & & & & & $<0.001^{b}$ \\
\hline No & $\begin{array}{l}3272 \\
(60.6)\end{array}$ & $4855(48.8)$ & $3796(39.9)$ & $2983(36.3)$ & $2314(33.2)$ & 4935 (29.5) & \\
\hline Yes & $\begin{array}{l}2125 \\
(39.4)\end{array}$ & $5100(51.2)$ & $5720(60.1)$ & 5225 (63.7) & $4662(66.8)$ & $11773(70.5)$ & \\
\hline Clinical pregnancy & & & & & & & $<0.001^{b}$ \\
\hline No & $\begin{array}{l}3495 \\
(64.8)\end{array}$ & 5341 (53.7) & $4246(44.6)$ & $3346(40.8)$ & 2663 (38.2) & 5701 (34.1) & \\
\hline Yes & $\begin{array}{l}1902 \\
(35.2)\end{array}$ & $4614(46.3)$ & $5270(55.4)$ & $4862(59.2)$ & $4313(61.8)$ & 11007 (65.9) & \\
\hline Live birth & & & & & & & $<0.001^{b}$ \\
\hline No & $\begin{array}{l}4015 \\
(74.4)\end{array}$ & $6422(64.5)$ & $5370(56.4)$ & $4274(52.1)$ & 3417 (49.0) & 7501 (44.9) & \\
\hline Yes & $\begin{array}{l}1382 \\
(25.6)\end{array}$ & $3533(35.5)$ & $4146(43.6)$ & 3934 (47.9) & 3559 (51.0) & 9207 (55.1) & \\
\hline
\end{tabular}

${ }^{a}$ Continuous data following normal distribution are described with mean \pm standard deviation, compared by ANOVA test; ${ }^{b}$ Categorical data are described with number (percentage), compared by Pearson's chi-square test; ${ }^{\mathrm{C}}$ Continuous data which don't follow normal distribution are described with median (quartiles), compared by Kruskal-Wallis test. Bold and italic: $p<0.05$, statistically significant. BMI, body mass index; FSH, follicle-stimulating hormone; E2, estradiol; COS, controlled ovarian stimulation; GnRH-a, gonadotropin-releasing hormone agonist; GnRH-

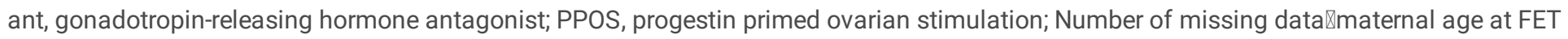
$=3$, maternal age at oocyte retrieval $=4$, infertility indication $=3841$, antral follicle counts $=2506$, basal FSH $=2807$, basal $\mathrm{LH}=3128, \mathrm{COS}$ protocols $=3125$, endometrial preparation regimens $=945$, endometrium thickness on transformation day $=15880$; number of embryos transferred $=2$; quality of embryos transferred $=3453$.

Table 5 Characteristics of oocyte retrieval cycles of complete cycles 


\begin{tabular}{|c|c|c|c|c|c|c|c|}
\hline \multirow[t]{2}{*}{ Factors } & \multicolumn{7}{|c|}{ E2 on trigger day $(\mathrm{pg} / \mathrm{ml})$} \\
\hline & $\begin{array}{l}<1000 \\
(N=7086)\end{array}$ & $\begin{array}{l}1000-2000 \\
(\mathrm{~N}=10780)\end{array}$ & $\begin{array}{l}2000-3000 \\
(\mathrm{~N}=8572)\end{array}$ & $\begin{array}{l}3000-4000 \\
(\mathrm{~N}=6458)\end{array}$ & $\begin{array}{l}4000-5000 \\
(\mathrm{~N}=5123)\end{array}$ & $\begin{array}{l}\geq 5000 \\
(\mathrm{~N}=11195)\end{array}$ & $p$ \\
\hline $\begin{array}{l}\text { Maternal age } \\
\text { (years) }\end{array}$ & $35.5 \pm 5.6$ & $33.2 \pm 5.3$ & $31.6 \pm 4.7$ & $30.6 \pm 4.4$ & $30.0 \pm 4.2$ & $29.6 \pm 3.9$ & $<0.01^{a}$ \\
\hline $\begin{array}{l}\text { Maternal BMI } \\
(\mathrm{kg} / \mathrm{m} 2)\end{array}$ & $23.1 \pm 3.2$ & $22.8 \pm 3.2$ & $22.3 \pm 3.1$ & $22.1 \pm 3.1$ & $22.0 \pm 3.0$ & $21.6 \pm 2.8$ & $<0.01^{a}$ \\
\hline $\begin{array}{l}\text { Infertility } \\
\text { indications }\end{array}$ & & & & & & & $<0.01^{b}$ \\
\hline $\begin{array}{l}\text { Male } \\
\text { factors }\end{array}$ & $372(6.0)$ & $966(9.8)$ & 995 (12.5) & $868(14.3)$ & 757 (15.7) & $1569(14.6)$ & \\
\hline Ovarian factor & $3314(53.0)$ & $2725(27.5)$ & $975(12.2)$ & $362(6.0)$ & $199(4.1)$ & $163(1.5)$ & \\
\hline Endometriosis & $343(5.5)$ & $688(7.0)$ & $641(8.0)$ & $477(7.9)$ & $373(7.7)$ & $802(7.4)$ & \\
\hline $\begin{array}{l}\text { Ovulatory } \\
\text { disorders }\end{array}$ & $393(6.3)$ & $1081(10.9)$ & $1101(13.8)$ & $956(15.8)$ & $831(17.2)$ & $2258(20.9)$ & \\
\hline $\begin{array}{l}\text { Pelvic/tubal } \\
\text { factor }\end{array}$ & $1591(25.5)$ & $3874(39.2)$ & $3797(47.6)$ & $2967(48.9)$ & $2337(48.4)$ & $5346(49.6)$ & \\
\hline Others & $235(3.8)$ & $558(5.6)$ & $474(5.9)$ & $432(7.1)$ & $336(7.0)$ & $643(6.0)$ & \\
\hline $\begin{array}{l}\text { Antral follicle } \\
\text { counts }\end{array}$ & $7.3 \pm 5.3$ & $10.3 \pm 6.2$ & $12.9 \pm 6.6$ & $14.4 \pm 6.3$ & $15.3 \pm 6.3$ & $16.9 \pm 6.5$ & $<0.01^{a}$ \\
\hline $\begin{array}{l}\text { Basal FSH } \\
\text { (IU/L) }\end{array}$ & $8.3(6.7,11.0)$ & $7.4(6.2,9.2)$ & $7.0(5.9,8.3)$ & $6.8(5.7,8.0)$ & $6.7(5.7,7.9)$ & $6.4(5.5,7.5)$ & $<0.01^{c}$ \\
\hline COS protocols & & & & & & & $<0.01^{b}$ \\
\hline GnRH-a based & $1759(28.9)$ & $5128(51.0)$ & $5051(61.3)$ & $4215(67.4)$ & $3119(62.5)$ & $8141(74.5)$ & \\
\hline $\begin{array}{l}\text { GnRH-ant } \\
\text { based }\end{array}$ & $1307(21.5)$ & 2927 (29.1) & $2137(25.9)$ & 1354 (21.6) & $1193(23.9)$ & 2066 (18.9) & \\
\hline PPOS & $565(9.3)$ & 376 (3.7) & 127 (1.5) & $55(0.88)$ & $26(0.52)$ & $33(0.30)$ & \\
\hline $\begin{array}{l}\text { Mild } \\
\text { stimulation }\end{array}$ & 2181 (35.8) & $1621(16.1)$ & $921(11.2)$ & $627(10.0)$ & $647(13.0)$ & $688(6.3)$ & \\
\hline Natural cycle & $272(4.5)$ & $5(0.05)$ & $1(0.01)$ & $4(0.06)$ & $2(0.04)$ & $2(0.02)$ & \\
\hline $\begin{array}{l}\text { E2 on trigger } \\
\text { day }(\mathrm{pg} / \mathrm{ml})\end{array}$ & $\begin{array}{l}629.6 \\
(395.0,821.7)\end{array}$ & $\begin{array}{l}1480.0 \\
(1243.0,1731.0)\end{array}$ & $\begin{array}{l}2463.0 \\
(2226.0,2723.0)\end{array}$ & $\begin{array}{l}3388.0 \\
(3117.0,3676.0)\end{array}$ & $\begin{array}{l}4516.0 \\
(4252.0,4802.0)\end{array}$ & $\begin{array}{l}6799.0 \\
(5794.0,8316.0)\end{array}$ & $<0.01^{c}$ \\
\hline $\begin{array}{l}\text { Oocytes } \\
\text { retrieved }\end{array}$ & $3.1 \pm 2.5$ & $6.3 \pm 3.9$ & $9.6 \pm 4.8$ & $12.0 \pm 5.6$ & $12.8 \pm 5.6$ & $16.9 \pm 6.6$ & $<0.01^{a}$ \\
\hline $\begin{array}{l}\text { Cumulative } \\
\text { Live birth }\end{array}$ & & & & & & & $<0.01^{b}$ \\
\hline No & $4732(66.8)$ & $5533(51.3)$ & 3329 (38.8) & $1954(30.3)$ & $1217(23.8)$ & $1813(16.2)$ & \\
\hline Yes & 2354 (33.2) & 5247 (48.7) & $5243(61.2)$ & 4504 (69.7) & 3906 (76.2) & 9382 (83.8) & \\
\hline
\end{tabular}

${ }^{a}$ Continuous data following normal distribution are described with mean \pm standard deviation, compared by ANOVA test; ${ }^{b}$ Categorical data are described with number (percentage), compared by Pearson's chi-square test; ${ }^{\mathrm{C}}$ Continuous data which don't follow normal distribution are described with median (quartiles), compared by Kruskal-Wallis test. Bold and italic: $p<0.05$, statistically significant; BMI, body mass index; FSH, follicle-stimulating hormone; E2, estradiol; COS, controlled ovarian stimulation; GnRH-a, gonadotropin-releasing hormone agonist; $\mathrm{GnRH}-$ ant, gonadotropin-releasing hormone antagonist; PPOS, progestin primed ovarian stimulation; Number of missing data: maternal age $=2$, maternal $\mathrm{BMI}=586$, infertility indication $=3415$, antral follicle counts $=2335$, basal FSH $=2330$, COS protocols $=2664$.

Table 6. Pregnancy outcomes of fresh embryo transfer cycles for groups stratified by estradiol (E2) on trigger day 


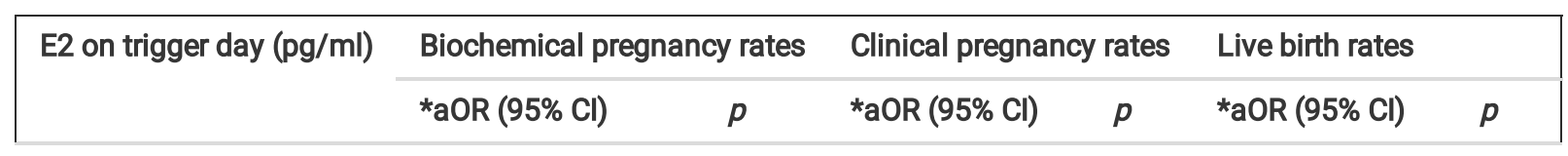

\begin{tabular}{|lllllll|}
\hline$<\mathbf{1 0 0 0}$ & Reference & & Reference & \multicolumn{3}{l|}{ Reference } \\
\hline $\mathbf{1 , 0 0 0 - 2 , 0 0 0}$ & $1.06(0.94,1.19)$ & 0.38 & $1.06(0.94,1.20)$ & 0.36 & $1.03(0.91,1.16)$ & 0.69 \\
\hline $\mathbf{2 , 0 0 0 - 3 , 0 0 0}$ & $1.12(0.99,1.27)$ & 0.10 & $1.11(0.97,1.27)$ & 0.12 & $1.06(0.93,1.21)$ & 0.40 \\
\hline $\mathbf{3 , 0 0 0 - 4 , 0 0 0}$ & $1.05(0.91,1.22)$ & 0.48 & $1.04(0.90,1.20)$ & 0.60 & $1.03(0.89,1.19)$ & 0.70 \\
\hline $\mathbf{4 , 0 0 0 - 5 , 0 0 0}$ & $1.04(0.89,1.22)$ & 0.64 & $1.07(0.91,1.25)$ & 0.44 & $1.02(0.87,1.20)$ & 0.79 \\
\hline $\mathbf{2 5 , 0 0 0}$ & $0.94(0.80,1.11)$ & 0.45 & $0.90(0.76,1.05)$ & 0.18 & $0.88(0.75,1.03)$ & 0.12 \\
\hline
\end{tabular}

*Adjusted with the maternal age at oocyte retrieval, body mass index, paternal age at oocyte retrieval, infertility type, infertility duration, infertility indications, antral follicle count, basal level of follicle-stimulating hormone, basal level of luteinizing hormone, controlled ovarian stimulation regimens, stimulation duration, total gonadotropin dose, LH on trigger day, progesterone on trigger day, fertilization method, and reproductive centers, the quality, number and developing days of embryos transferred, and the endometrium thickness on trigger day. Multiplicity was adjusted with Dunnett's test. Bold and italic: $\mathrm{P}<0.05$, statistically significant. aOR, adjusted odds ratio; $\mathrm{Cl}$, confidence interval.

Table 7. Pregnancy outcomes of frozen-thawed embryo transfer cycles for groups stratified by estradiol (E2) on trigger day

\begin{tabular}{|c|c|c|c|c|c|c|}
\hline \multirow[t]{2}{*}{ E2 on trigger day (pg/ml) } & \multicolumn{2}{|c|}{ Biochemical pregnancy rates } & \multicolumn{2}{|c|}{ Clinical pregnancy rates } & \multicolumn{2}{|l|}{ Live birth rates } \\
\hline & *aOR $(95 \% \mathrm{Cl})$ & $p$ & *aOR $(95 \% \mathrm{Cl})$ & $p$ & *aOR $(95 \% \mathrm{Cl})$ & $p$ \\
\hline$<1000$ & Reference & & Reference & & Reference & \\
\hline $1,000-2,000$ & $1.07(0.95,1.20)$ & 0.28 & $1.04(0.92,1.17)$ & 0.58 & $1.01(0.90,1.14)$ & 0.82 \\
\hline $2,000-3,000$ & $1.16(1.02,1.32)$ & 0.03 & $1.14(1.00,1.30)$ & 0.05 & $1.08(0.95,1.22)$ & 0.27 \\
\hline $3,000-4,000$ & $1.15(0.99,1.31)$ & 0.05 & $1.14(0.99,1.31)$ & 0.06 & $1.10(0.96,1.27)$ & 0.15 \\
\hline $4,000-5,000$ & $1.16(1.00,1.34)$ & 0.05 & $1.14(0.99,1.32)$ & 0.07 & $1.12(0.97,1.29)$ & 0.13 \\
\hline$\geq 5,000$ & $1.21(1.06,1.40)$ & 0.01 & $1.21(1.06,1.39)$ & 0.01 & $1.20(1.05,1.37)$ & 0.01 \\
\hline
\end{tabular}

*Adjusted with the maternal age at oocyte retrieval, body mass index, paternal age at oocyte retrieval, infertility type, infertility duration, infertility indications, antral follicle count, basal level of follicle-stimulating hormone, basal level of luteinizing hormone, controlled ovarian stimulation regimens, stimulation duration, total gonadotropin dose, LH on trigger day, progesterone on trigger day, fertilization method, and reproductive centers, endometrium preparation regimen, the quality, number and developing days of embryos transferred, and endometrium thickness on transformation day. Multiplicity was adjusted with Dunnett's test. Bold and italic: $P<0.05$, statistically significant. aOR, adjusted odds ratio; $\mathrm{Cl}$, confidence interval.

Table 8. Cumulative live birth rates of groups stratified by estradiol (E2) on trigger day

\begin{tabular}{|llllll|}
\hline E2 on trigger day $(\mathrm{pg} / \mathrm{ml})$ & *aOR $(\mathbf{9 5} \% \mathrm{Cl})$ & $\boldsymbol{p}$ & E2 on trigger day $(\mathrm{pg} / \mathrm{ml})$ & *aOR $(95 \% \mathrm{Cl})$ & $p$ \\
\hline$<\mathbf{1 0 0 0}$ & & & $\mathbf{8 , 0 0 0 - 1 , 0 0 0 0}$ & $1.92(1.46,2.54)$ & $<0.01$ \\
\hline $\mathbf{1 , 0 0 0 - 2 , 0 0 0}$ & $1.33(1.13,1.56)$ & $<0.01$ & $\mathbf{1 0 , 0 0 0 - 1 2 , 0 0 0}$ & $1.82(1.26,2.65)$ & $<0.01$ \\
\hline $\mathbf{2 , 0 0 0 - 3 , 0 0 0}$ & $1.56(1.31,1.85)$ & $<0.01$ & $\mathbf{1 2 , 0 0 0 - 1 4 , 0 0 0}$ & $1.92(1.09,3.41)$ & $\mathbf{0 . 0 3}$ \\
\hline $\mathbf{3 , 0 0 0 - 4 , 0 0 0}$ & $1.68(1.39,2.02)$ & $<0.01$ & $\mathbf{1 4 , 0 0 0 - 1 6 , 0 0 0}$ & $1.51(0.72,3.1)$ & 0.27 \\
\hline $\mathbf{4 , 0 0 0 - 5 , 0 0 0}$ & $1.83(1.50,2.24)$ & $<0.01$ & $\mathbf{1 6 , 0 0 0 - 1 8 , 0 0 0}$ & $1.35(0.14,12.83)$ & 0.79 \\
\hline $\mathbf{5 , 0 0 0 - 6 , 0 0 0}$ & $1.86(1.49,2.33)$ & $<\mathbf{0 . 0 1}$ & $\mathbf{1 8 , 0 0 0 - 2 0 , 0 0 0}$ & $0.67(0.06,7.06)$ & 0.74 \\
\hline $\mathbf{6 , 0 0 0 - 8 , 0 0 0}$ & $1.88(1.51,2.34)$ & $<0.01$ & $\mathbf{2} \mathbf{2 0 , 0 0 0}$ & $0.50(0.03,8.7)$ & 0.64 \\
\hline
\end{tabular}

*Adjusted with the maternal age at oocyte retrieval, body mass index, paternal age at oocyte retrieval, infertility type, infertility duration, infertility indications, antral follicle count, basal level of follicle-stimulating hormone, basal level of luteinizing hormone, controlled ovarian stimulation regimens, stimulation duration, total gonadotropin dose, LH on trigger day, progesterone on trigger day, fertilization method, and 
reproductive centers, and number of oocytes retrieved. Multiplicity was adjusted with Dunnett's test. Bold and italic: $P<0.05$, statistically significant. aOR, adjusted odds ratio; $\mathrm{Cl}$, confidence interval.

Due to technical limitations, Table 1 is only available as a download in the Supplemental Files section.

\section{Figures}

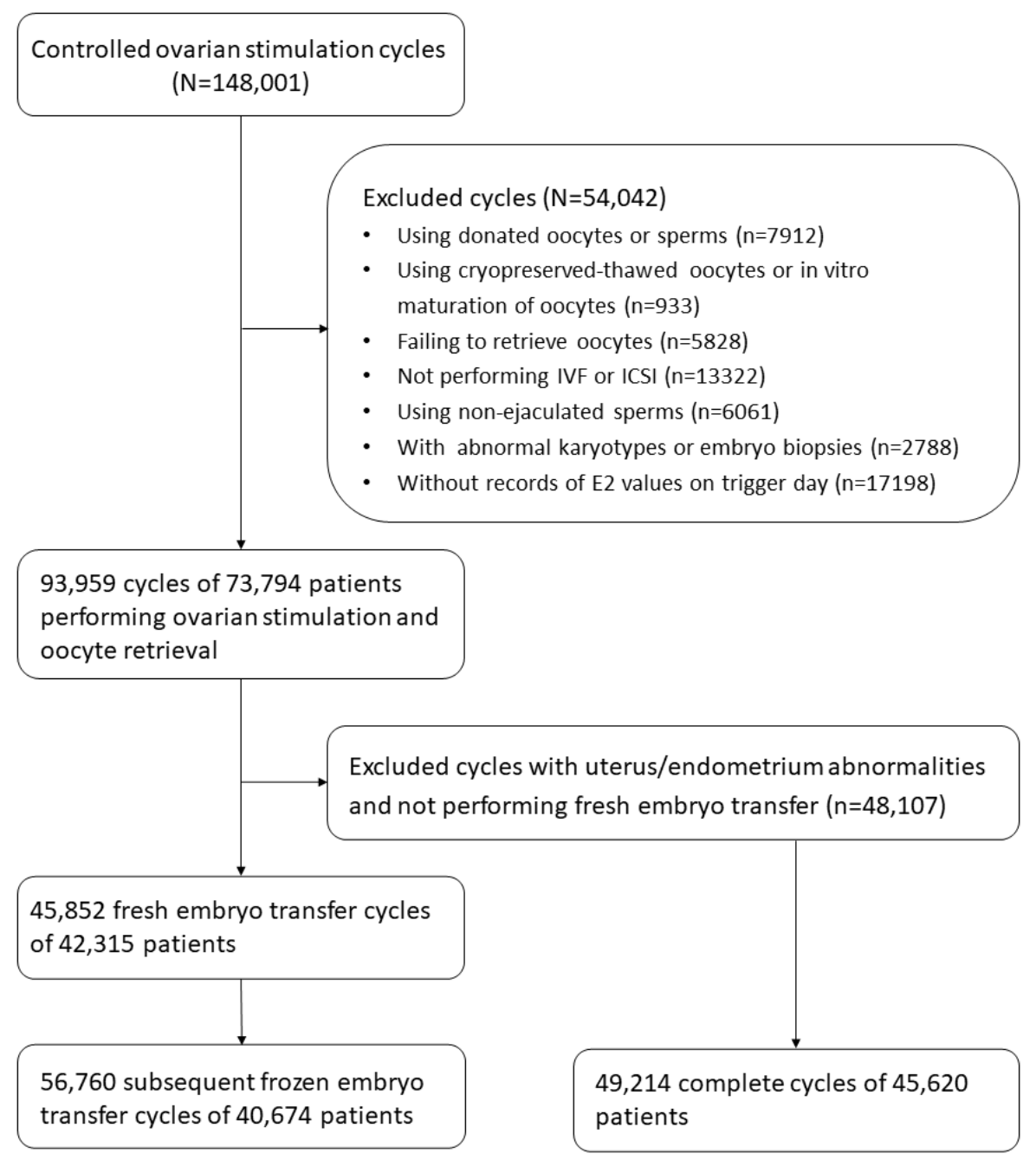

\section{Figure 1}

Flowchart of the study 


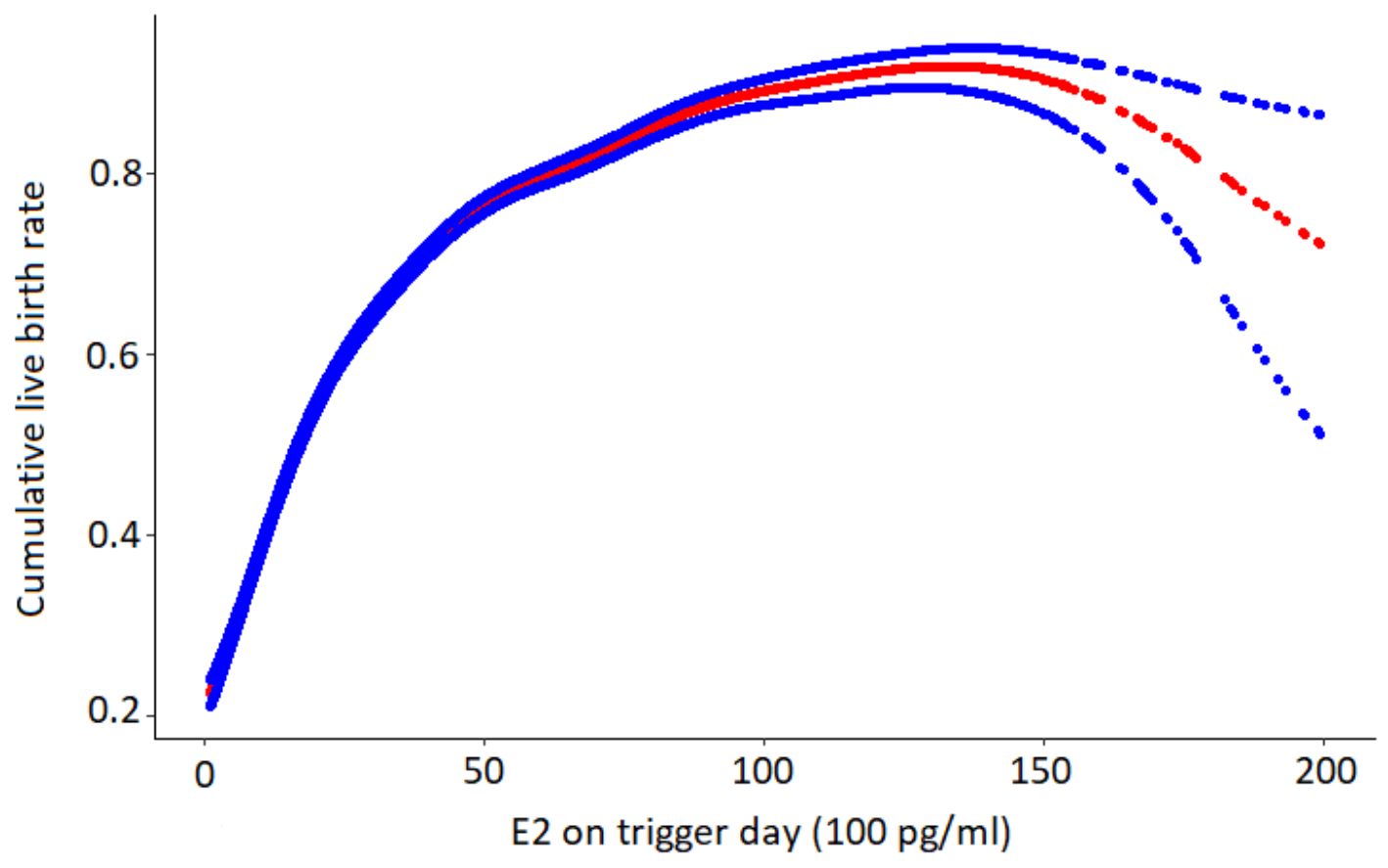

Figure 2

The smooth fitting curve for cumulative live birth and estradiol on trigger day.

\section{Supplementary Files}

This is a list of supplementary files associated with this preprint. Click to download.

- Table1.docx 